\title{
A Palpable Miss: the Underrepresentation of History and Physical Errors as Identified by Internal Medicine Residents for Morbidity and Mortality Conference
}

J Gen Intern Med 37(1):264-5

DOI: $10.1007 / \mathrm{s} 11606-020-06374-0$

(C) Society of General Internal Medicine 2021

\section{INTRODUCTION}

Diagnostic errors contribute to morbidity, mortality, and increased healthcare costs. ${ }^{1-4}$ Morbidity and mortality conferences (M\&MCs) in academic medical centers enable trainees to discuss, teach, and learn from errors. Little is known about the types of errors that residents identify in cases submitted to M\&MCs. We analyzed M\&MC cases submitted by residents to understand the range of diagnostic errors and teaching points made in each case.

\section{METHODS}

We studied 67 consecutive cases submitted to M\&MC by internal medicine residents at our institution from July 2019 to February 2020. Each inpatient service submitted one case per month, providing free-text responses that detailed the case summary, the adverse outcome/error, and teaching points. Cases were selected by medical residents (with optional feedback from their attendings). Guidelines for case selection included: unexpected death, unexpected complication causing major morbidity, diagnostic error resulting in delay of appropriate treatment, or potentially incorrect therapeutic decisions delaying appropriate treatment or causing harm. Systemsrelated errors were strongly discouraged for case selection.

Diagnostic errors were defined as missed opportunities to make correct or timely diagnoses. We applied the Diagnostic Error Evaluation and Research (DEER) taxonomy, which classifies errors into seven stages in the diagnostic process and types of process failure. ${ }^{5}$ The seven stages are access/ presentation, history-taking, physical examination, testing, assessment, referral, and follow-up. Multiple types of process failures may occur at each stage (e.g., physical examination includes process failures in identifying critical findings, inaccurately interpreting or weighing the significance of a finding,

\section{Prior Presentations None.}

Received September 14, 2020

Accepted November 30, 2020

Published online January 14, 2021 or failing to follow up). We also determined whether teaching points related to the types of diagnostic errors we identified.

Three faculty physicians independently reviewed all cases, then discussed cases for which there was not complete agreement across all reviewers. Forty of 67 cases required in-depth discussion and adjudication by committee consensus. This study was exempted from full review by the Institutional Review Board at Weill Cornell Medicine.

\section{RESULTS}

Among 67 case submissions to M\&MC, 43 (64\%) involved at least one diagnostic error. The most common stage in the diagnostic process with errors was assessment $(31 / 43,72 \%)$, followed by testing $(63 \%)$, referrals or consultations $(21 \%)$, physical examination (19\%), and history (14\%). One case involved an error with access to care and none involved follow-up errors.

We identified 83 occurrences of different types of process failures within individual cases (Table 1). Forty-seven of 83 $(57 \%)$ process failures were addressed by residents' teaching points, including $75 \%$ of errors in assessment and $63 \%$ of those in the testing stages of diagnosis. Teaching points were least likely to identify errors such as history-taking (33\%), physical examination $(25 \%)$, and referral $(22 \%)$ points.

\section{DISCUSSION}

This study demonstrates that while a range of diagnostic errors were present in cases submitted to M\&MC, residents identified errors in history-taking and physical examination less frequently and devoted less attention during teaching points than to errors in assessment and testing. We believe this represents a common culture in graduate medical training that far more attention is placed on gathering laboratory data than on rigorous history-taking and physical examination.

Resident physicians may feel less comfortable with historytaking and physical examination, skills that take years to develop, than with the interpretation of diagnostic tests. Accordingly, they may feel ill-equipped to prioritize bedside diagnostic skills. In addition, attending physicians may give very little emphasis on their resident teaching to the potential impact of the history and physical examination on management decisions. 
Table 1 Types of Diagnostic Error in Morbidity and Mortality Conference Case Submissions

\begin{tabular}{|c|c|c|}
\hline Stage in diagnostic process & Type of diagnostic error (i.e., what went wrong?) & No. $(\%)(N=43$ cases $)$ \\
\hline \multirow[t]{2}{*}{ 1. Access/presentation } & Denied care & $1(2 \%)$ \\
\hline & Delayed presentation & $0(0 \%)$ \\
\hline \multirow[t]{4}{*}{ 2. History } & Failure/delay in eliciting critical piece of history data & $1(2 \%)$ \\
\hline & Inaccurate/misinterpretation & $3(7 \%)$ \\
\hline & Suboptimal weighing & $2(5 \%)$ \\
\hline & Failure/delay to follow-up & $0(0 \%)$ \\
\hline \multirow[t]{4}{*}{ 3. Physical examination } & Failure/delay in eliciting critical physical examination finding & $3(7 \%)$ \\
\hline & Inaccurate/misinterpreted & $5(12 \%)$ \\
\hline & Suboptimal weighing & $0(0 \%)$ \\
\hline & Failure/delay to follow-up & $0(0 \%)$ \\
\hline \multirow[t]{6}{*}{ 4. Testing } & Failure/delay in ordering needed test(s) & $12(28 \%)$ \\
\hline & Failure/delay in performing ordered test(s) & $1(2 \%)$ \\
\hline & Suboptimal test sequencing & $2(5 \%)$ \\
\hline & Ordering of wrong test $(\mathrm{s})$ & $2(5 \%)$ \\
\hline & Failed/delayed follow-up action on test result & $3(7 \%)$ \\
\hline & Erroneous clinician interpretation of test & $7(16 \%)$ \\
\hline \multirow[t]{6}{*}{ 5. Assessment } & Failure/delay in considering the correct diagnosis & $14(33 \%)$ \\
\hline & Too much weight to low(er) probability/priority diagnosis & $1(2 \%)$ \\
\hline & Too little consideration of high(er) probability/priority diagnosis & $3(7 \%)$ \\
\hline & Too much weight on competing diagnosis & $1(2 \%)$ \\
\hline & Failure to appreciate urgency/acuity of illness & $5(12 \%)$ \\
\hline & Failure/delay in recognizing complication(s) & $8(19 \%)$ \\
\hline \multirow[t]{4}{*}{ 6. Referral or consultation } & Failure/delay in ordering needed referral & $3(7 \%)$ \\
\hline & Inappropriate/unneeded referral & $2(5 \%)$ \\
\hline & Suboptimal consultation diagnostic performance & $0(0 \%)$ \\
\hline & Failed/delayed communication/follow-up of consultation & $4(9 \%)$ \\
\hline \multirow[t]{2}{*}{ 7. Follow-up } & Failure to refer to setting for close monitoring & $0(0 \%)$ \\
\hline & Failure/delay in timely follow-up/rechecking of patient & $0(0 \%)$ \\
\hline
\end{tabular}

There are several study limitations. We studied a single academic medical center, which may limit the generalizability of our findings. There are significant limitations with adjudicating diagnostic error from chart review. Furthermore, we did not speak with the clinicians involved or analyze the content of discussions during M\&MC. It is possible that other diagnostic errors or teaching points emerged during conference discussions.

We found that our case reviews in this study facilitated rich discussions not only about diagnostic errors but also about what is diagnostic excellence. Since M\&MC is an opportunity to learn from errors and hone diagnostic skills, workshops involving similar analysis of cases using a comprehensive framework to classify diagnostic errors could increase residents' appreciation for the full range of diagnostic errors. Assuring that attending physicians pay sufficient attention to history and physical examination is no less essential.

Acknowledgments: We would like to acknowledge chief residents Daniel Choi, Maria Pabon, and Zachary Sherman for their contributions.

Justin J. Choi, $M D^{1}$

Jigar H. Contractor, $M D^{1}$

Todd S. Cutler, $M D^{1}$

Martin F. Shapiro, MD, $M P H^{1}$

${ }^{1}$ Division of General Internal Medicine, Department of Medicine, Weill Cornell Medicine,

New York, NY, USA

Corresponding Author: Justin J. Choi, MD; Division of General Internal Medicine, Department of Medicine, Weill Cornell Medicine, New York, NY, USA (e-mail: juc9107@med.cornell.edu).
Funding Dr. Choi is supported by the National Institutes of Health/ National Center for Advancing Translational Sciences grant KL2-TR002385 .

\section{Compliance with Ethical Standards:}

Conflict of Interest: Dr. Choi has received research support and consulting fees from Roche Diagnostics and Allergan unrelated to thework in this manuscript. The other co-authors have no disclosures.

\section{REFERENCES}

1. Hayward RA. Counting deaths due to medical errors. JAMA. 2002;288(19):2404-5; author reply 2405. https://doi.org/10.1001/jama. 288.19.2404-jlt1120-2-2

2. Saber Tehrani AS, Lee H, Mathews SC, et al. 25-Year summary of US malpractice claims for diagnostic errors 1986-2010: an analysis from the National Practitioner Data Bank. BMJ Qual Saf. 2013;22(8):672-680. https://doi.org/10.1136/bmjqs-2012-001550.

3. Singh H, Meyer AND, Thomas EJ. The frequency of diagnostic errors in outpatient care: estimations from three large observational studies involving US adult populations. BMJ Qual Saf. 2014;23(9):727-731. https://doi.org/10.1136/bmjqs-2013-002627.

4. Singh H, Giardina TD, Meyer AND, Forjuoh SN, Reis MD, Thomas EJ. Types and origins of diagnostic errors in primary care settings. JAMA Intern Med. 2013;173(6):418-425. https://doi.org/10.1001/ jamainternmed.2013.2777.

5. Schiff GD, Kim S, Abrams R, et al. Diagnosing Diagnosis Errors: Lessons from a Multi-institutional Collaborative Project. In: Henriksen K, Battles JB, Marks ES, Lewin DI, eds. Advances in Patient Safety: From Research to Implementation (Volume 2: Concepts and Methodology). Advances in patient safety. Rockville, MD: Agency for Healthcare Research and Quality (US); 2005.

Publisher's Note: Springer Nature remains neutral with regard to jurisdictional claims in published maps and institutional affiliations. 